\title{
The Impact Performance of Woven-Fabric Thermoplastic and Thermoset Composites Subjected to High-Velocity Soft- and Hard-Impact Loading
}

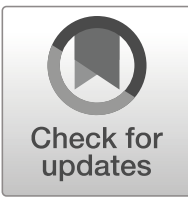

\author{
Jun Liu ${ }^{1} \cdot$ Haibao $\mathrm{Liu}^{1} \cdot$ Cihan Kaboglu ${ }^{1} \cdot$ Xiangshao Kong $^{1,2} \cdot$ Yuzhe Ding $^{1} \cdot$ \\ Hui Chai ${ }^{1,3} \cdot$ Bamber R. K. Blackman ${ }^{1} \cdot$ Anthony J. Kinloch ${ }^{1} \cdot$ John P. Dear $^{1}$ (D)
}

Received: 13 June 2019 / Accepted: 29 August 2019/Published online: 1 November 2019

(C) The Author(s) 2019

\begin{abstract}
The present paper investigates the impact performance of woven-fabric carbon-fibre composites based upon both thermoplastic- and thermoset-matrix polymers under highvelocity impact loading by conducting gas-gun experiments at impact velocities of up to $100 \mathrm{~m} . \mathrm{s}^{-1}$. The carbon-fibre reinforced-polymers (CFRPs) are impacted using soft- (i.e. gelatine) and hard- (i.e. aluminium-alloy) projectiles to simulate either a soft bird-strike or a hard foreign-body impact (e.g. runway debris), respectively, on typical composites employed in civil aircraft. The out-of-plane displacements of the impacted composite specimen are obtained by means of a three-dimensional Digital Image Correlation (DIC) system for the soft-projectile impact on the composites and the extent of damage is assessed both visually and by using portable $\mathrm{C}$-scan equipment. The perforation resistance and energy absorbing capability of the composites are also studied by performing high-velocity impact experiments using the hard-projectile and the resulting extent and type of damage are identified. In addition, a Finite Element (FE) model is also developed to investigate the interaction between the projectile and the composite target.
\end{abstract}

Keywords Thermoplastic composites · High-velocity impact - Digital image correlation (DIC) · Ultrasonic C-scanning $\cdot$ Bird-strikes $\cdot$ Runway debris damage $\cdot$ Numerical modelling

John P. Dear

j.dear@imperial.ac.uk

1 Department of Mechanical Engineering, Imperial College London, South Kensington Campus, London SW7 2AZ, UK

2 Wuhan University of Technology, No. 122 Luoshi Road, Wuhan, Hubei 430070, People's Republic of China

3 The First Aircraft Institute, No.1 East Renmin Road, Yanliang District, Xi'an, Shanxi 710089, People's Republic of China 


\section{Introduction}

Fibre/polymer-matrix composite materials have become widespread in the transportation and energy industries. For example, the automotive, rail, marine and wind turbine industries currently make use of such composites, as well as the aviation industry where direct operating costs and performance favour composites. Amongst these materials, to achieve the highest level of performance, carbon-fibre reinforced-polymers (CFRPs) have attracted the most attention. These types of composites have been extensively employed in modern civilian aircraft due to their excellent stiffness, strength, fatigue and corrosion properties. In the latest generation of commercial aircraft, such as the 'Boeing Dreamliner B787' and the 'Airbus A350', the fuselage as well as the wing structures are manufactured using CFRPs. Indeed, the composites used account for about fifty [1] and fifty-three [2] per cent of the total weight of these aircraft, respectively. However, such composite materials do have some shortcomings. For example, they are vulnerable to impact damage due to foreign objects ranging from small runway debris to bird-strikes [3-6]. Foreign-object damage (FOD) poses serious threats to aircraft, as such damage can, in the worst case, lead to major structural damage in critical aircraft components. The US Federal Aviation Administration (FAA) stated in 2019, that there were 197,833 bird-strikes reported to the FAA from 1990 to 2017 [6]. More than twohundred and sixty-three aircraft were seriously damaged, and over two-hundred and eight-seven people were killed by wildlife strikes from 1988 to November 2018 [6]. In the case of runway debris hazards, the aviation industry estimates that the cost of repairing the affected aircraft structures as being over sixty million dollars in 1996 [7]. As a result of the increasing number of these incidents, more attention has been paid recently to the impact damage resistance of CFRPs.

With this in mind, the impact performances of composites, such as the conventional nontoughened and toughened thermosetting epoxy-matrix composites [7-11], thermoplasticmatrix composites [12-14], and three-dimensional woven-fabric fibre composites [15-17], have been studied. In industrial applications, the carbon-fibre reinforced-epoxy (CF/epoxy) composites have been extensively employed in civil aircraft, due to their relatively high performance and the relative ease of manufacturing large and complex structures from this type of composite material $[18,19]$. However, the industrial interest in fibre composites employing a thermoplastic-polymer matrix is growing, due to their excellent inherent properties, e.g. relatively high toughness, eco-friendly manufacture and recyclability [20-22]. The thermoplastic polymer matrix poly(ether-ether ketone) (PEEK), which is a high performance ductile semi-crystalline thermoplastic, has been the subject of most interest. Indeed, carbonfibre reinforced-PEEK (CF/PEEK) composites have captured much attention from the aviation industry and it has been considered as a promising material for the primary structure of aircraft. In order to further understand and compare the impact performance of CF/PEEK and CF/ epoxy composites, these two types of composite materials were chosen for the present study.

To employ such composites on aircraft an evaluation on their impact resistance is clearly necessary. For example, Vieille et al. [23] have identified different failure mechanisms when CF/PEEK and CF/epoxy composites have been subjected to low-velocity impacts. The impact damage was inspected using an ultrasonic C-scan system after a dropweight impact test had been conducted. For similar impact velocities, larger damage areas were found to be present in the CF/epoxy composites, compared to the CF/PEEK composites. Other studies have reached the same conclusion [8, 24-26]. However, the impact 
velocity associated with a drop-weight test is too slow to simulate a bird-strike or a foreign-body impact, which are frequently associated with impact velocities of over $50 \mathrm{~m} \cdot \mathrm{s}^{-1}$. Moreover, a significant change in the impact velocity may result in a different impact response of the composite material [27, 28]. Therefore, the impact velocities employed for laboratory experiments should be selected to be in a similar range to those expected for the likely in-service impact events. Cantwell et al. [27, 29-32] have performed a number of studies on the high-velocity impact responses of CF/epoxy composites, in which specimens with various lay-up configurations and thicknesses were evaluated. The energy-absorbing capability and failure mechanisms of these composites were determined and a model was developed to predict the degree of perforation of the impacted target specimen. This model enabled the evaluation of the effects of target thickness, and other factors, on the threshold impact velocity, and the associated impact energy, for damage initiation and for perforation of the composite target. Multiple nondestructive inspection (NDI) techniques, including ultrasonic C-scanning, X-radiography and optical microscopy, were employed to assess the resulting damage in the composites. Morita et al. [28] have studied the impact resistance of CF/PEEK and CF/epoxy composites when subjected to a high-velocity impact using a hard-projectile with a hemispherical end. However, it has been found that using a hard-projectile, where the deformation of the projectile is negligible upon impacting the composite target, is an inappropriate projectile to use to simulate a bird-strike [33, 34]. For this reason, real birds have often been employed to conduct high-velocity impact tests in the aviation industry. However, this has several disadvantages, including lack of repeatability and control on the orientation, homogeneity and isotropy of the projectile [35-37]. To overcome these drawbacks, Wilbeck [33] proposed a statistical method to optimise the shape and dimension of the projectile, as well as its material properties and impact velocity, to adequately simulate a bird-strike. It was recommended by Wilbeck and Rand [35] that a gelatine projectile, with a length-to-diameter ratio of two and a density of $1.03 \mathrm{~g} . \mathrm{cm}^{-3}$, be used for small-scale laboratory tests and that such a gelatine soft-projectile could provide a high level of accuracy when simulating the most hazardous bird-strikes.

Along with the development of the experimental methodology, various numerical approaches have been employed to model the impact events on composites [38, 39]. For example, Nishikawa et al. [38] presented a numerical simulation based on the Lagrange multiplier method to predict the impact-induced deformation and damage of composites subjected to high-velocity soft-body impacts. In this method, severe contact-induced deformation caused by a relatively large contact force can be effectively determined by adjusting the time-scale by using a small time step. Liu et al. [39] used an explicit Finite Element (FE) code to predict damage in a composite leading edge. The Smoothed Particle Hydrodynamic (SPH) method was used to model the deformation and flow of the soft-body gelatine projectile, which was employed to simulate a bird-strike. In the SPH method, the FE mesh for the impacting body is replaced by interacting particles, that are able to better represent the deformation and flow of the projectile over the target.

The present paper investigates the impact performance of woven-fabric carbon-fibre composites based upon both thermoplastic- and thermoset-matrix polymers under highvelocity impact loading by conducting gas-gun experiments at impact velocities of up to $100 \mathrm{~m} . \mathrm{s}^{-1}$. The CFRPs are impacted using soft- (i.e. gelatine) and hard- (i.e. aluminium-alloy) projectiles to simulate either a soft bird-strike or a hard foreign-body impact (e.g. runway debris), respectively, on typical composites employed in civil aircraft. 


\section{Materials and Specimens}

\subsection{The Composites}

The CF/PEEK and CF/epoxy composite specimens used in this study were made from two different woven-fabric prepregs (Torayca T300/Victrex PEEK 150PF and Torayca T300/C-MP epoxy CP009-3, respectively) and were manufactured by Haufler Ltd., Germany. The epoxy is a non-toughened material and is hot cured, see below for details. The CF/PEEK pre-pregs were consolidated using press moulding at $390 \pm 10^{\circ} \mathrm{C}$, whilst the $\mathrm{CF} /$ epoxy pre-pregs were cured via autoclave processing at $180 \pm 5^{\circ} \mathrm{C}$. The specimens were machined, using a waterjet cutter, from large plaques into $140 \times 140 \mathrm{~mm}$ test specimens. Both types of specimen had a nominal thickness of $2 \mathrm{~mm}$. To achieve this thickness, seven plies of the thermoplastic prepreg, with a nominal $50 \%$ volume fraction of fibres, were used for the CF/PEEK specimens and eight plies of the thermoset pre-preg, with a nominal 55\% fibre volume fraction, were used for the CF/epoxy specimens. The overall density of the CF/PEEK and CF/epoxy composite specimens was $1.54 \mathrm{~g} . \mathrm{cm}^{-3}$ and $1.57 \mathrm{~g} . \mathrm{cm}^{-3}$, respectively. (It should be noted that the objectives here were (a) to achieve virtually the same density for the two types of composites (i.e. the CF/PEEK and the CF/epoxy composites) and (b) for the specimens made from the two types of composites to have very similar values of thickness.)

\subsection{The Test Specimens}

The 3D DIC system was employed in the soft-projectile impact experiments to record the deformation of the CF/PEEK and CF/epoxy specimens. Prior to undertaking the experiments, all the specimens were kept under a temperature of $22 \pm 0.5{ }^{\circ} \mathrm{C}$ and a humidity of $50 \pm 2 \%$ for $24 \mathrm{~h}$. The non-impacted surface (i.e. the rear surface of the specimen) of the CFRP specimens were prepared according to the instructions of the manufacturer of the DIC system [40]. The target composite specimens were therefore painted with a matt-white acrylic paint, which was used to avoid excessive light reflection from the specimens. A random speckle-pattern, shown in Fig. 1, was hand-painted on the white surface using a matt-black marker to achieve the maximum contrast. The size of the black speckles was approximately $1.5 \mathrm{~mm}$. The specimens were fixed between two steel supporting plates, both with a $70 \times 70 \mathrm{~mm}$ opening, and twelve M8 bolts were used to fasten the steel plates together. A schematic drawing of the steel plates and the specimen is shown in Fig. 2.

Fig. 1 Specimen dimensions and the DIC pattern on the nonimpacted surface (i.e. the rear surface of the sample) of the test specimen. (Dimensions are in $\mathrm{mm}$ )

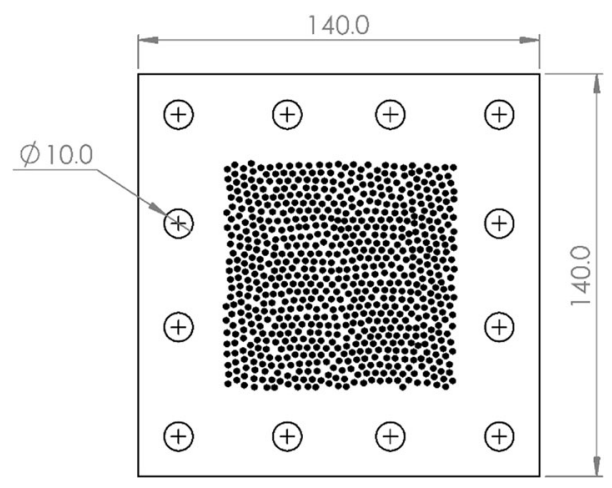


3D View

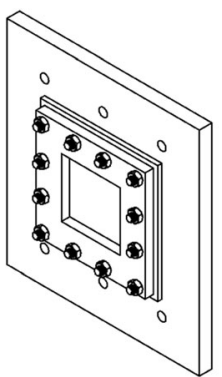

Cross-section View

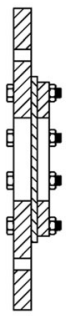

Side View

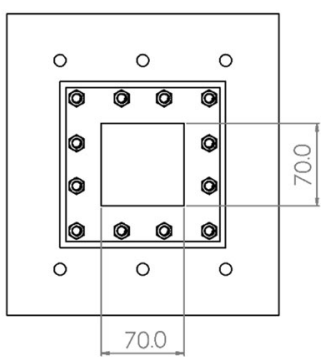

Fig. 2 Schematic of the support for the composite test specimen. (Dimensions are in $\mathrm{mm}$ )

\section{Experimental procedures1}

\subsection{Projectiles}

In order to simulate the impact of a bird-strike and runway debris on the composites, gelatine projectiles (to represent a relatively soft-projectile, e.g. a bird-strike) and aluminium-alloy projectiles (to represent a hard-projectile, e.g. runway debris) were used in the gas-gun experiments, as shown in Fig. 3. New projectiles were employed for each impact test.

Now gelatine has been identified as a good substitute material to simulate birds to overcome the drawbacks of using real birds for the impact tests, as discussed above. The gelatine projectile generates a similar level of initial shock-wave pressure as that experienced in a typical birdstrike, which is important in determining the extent and type of local damage that results in the impacted composite [35]. The gelatine projectiles employed were based on the bird model developed by Wilbeck and Rand [35]. Namely, a cylindrical mould was employed so that the soft gelatine projectile could be cast into the appropriate shape. A gelatine solution of $3 \%$ by weight was poured into the mould and heated in an environmental chamber at a temperature of $4-6{ }^{\circ} \mathrm{C}$ for $12 \mathrm{~h}$ to give a nominal mass of $20 \mathrm{~g}$. These gelatine projectiles were taken out from a refrigerator a few minutes before being employed in the gas-gun test, as they could only be exposed to ambient temperature for approximately half an hour before they lost their shape. Furthermore, the $3 \mathrm{wt} \%$ gelatine projectiles possessed a Shore hardness A of 0 to 5 and this enabled them to withstand the inertial loads during being launched from the gas gun. It is important to note that the shape of the gelatine projectile from being fired to impacting the target remained essentially unchanged, i.e. no stretching or compressing of the projectile occurred. To achieve this a sabot, $40 \mathrm{~mm}$ in diameter, was used to provide the projectile acceleration that was required and to reduce the friction between the soft-projectile and the barrel of the gas-gun.

The hard aluminium-alloy projectiles were machined from 7075-T6 aluminium-alloy. These gave a hard-impact event, for example as might be experienced by impact from runway debris. The aluminium-alloy projectiles had a nominal mass of $28 \mathrm{~g}$ and a nominal diameter of $24.9 \mathrm{~mm}$, which is slightly smaller than the diameter of $25 \mathrm{~mm}$ of the barrel of the gas gun. This was necessary in order for the aluminium-alloy projectiles to achieve a reproducible maximum velocity.

\subsection{Gas-Gun Set-up}

Two different set-ups of the gas gun were used to assess the dynamic deformation and ballistic response of the composites dependent upon whether the high-velocity impact was via the 
a

\section{Gelatine Projectile}

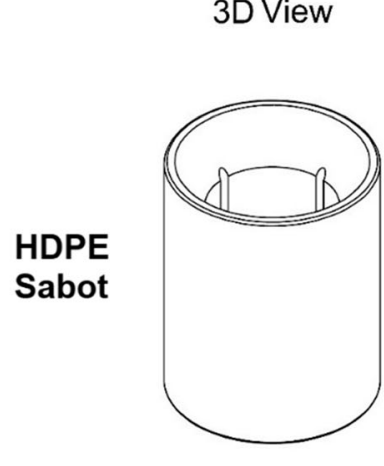

b

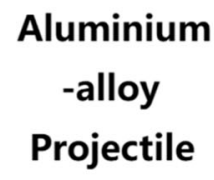

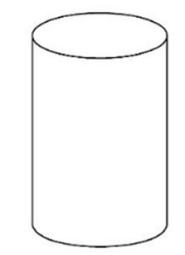

3D View

3D View

3D View

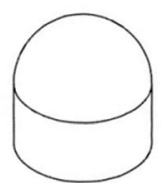

Side View

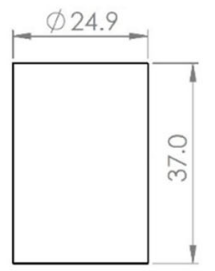

Cross-section View

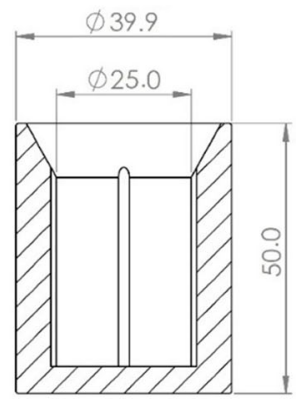

Side View

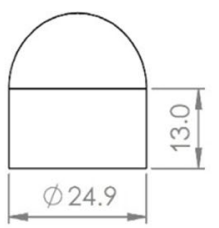

Photo View

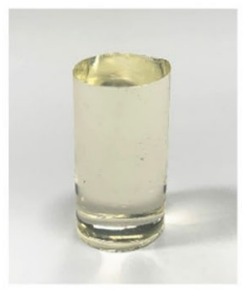

Photo View

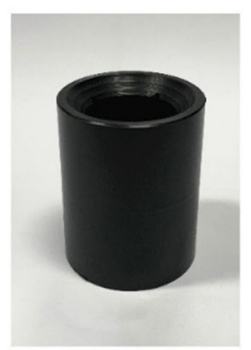

Photo View

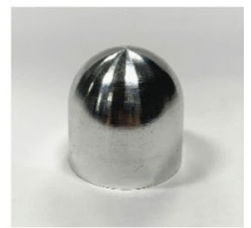

Fig. 3 Projectiles and sabot for soft- and hard-impact tests: (a) flat-fronted soft gelatine projectile and HDPE sabot and (b) hemi-spherical head of the hard aluminium-alloy projectile. (Dimensions are in $\mathrm{mm}$ )

relatively soft- or the hard-projectile. In both set-ups, helium gas was used to feed a four-litre pressure vessel and was released into to a three-metre long barrel by a fast-acting pneumatic value. The velocity of the projectile was controlled by changing the pressure of the vessel and measured by two pairs of infrared radiation sensors located at the end of the barrel. The distance from the end of the barrel to the specimen was $10 \mathrm{~cm}$ and any difference in the velocity of the projectile measured at the exit point from the barrel compared with that upon it impacting the composite specimen was less than $\pm 1 \%$. All tests were performed in a laboratory equipped with a constant environmental system giving a temperature of $22 \pm 0.5{ }^{\circ} \mathrm{C}$ and a humidity of $50 \pm 2 \%$.

For 'Set-up I', for the impact by the soft-gelatine projectile, a 3D DIC technique was employed to monitor the out-of-plane displacements of the specimens, which was measured from the deformations of the non-impacted (i.e. rear) surface of the composite specimen via the random black speckle-pattern. High-speed 3D DIC was employed to track the deformation history of the rear surface of the composite target specimen. Two synchronized high-speed cameras (i.e. 'Phantom Miro M/R/LC310' cameras supplied by Vision Research Phantom, USA) were placed behind the target chamber at a distance of $925 \mathrm{~mm}$ from the centre point of 
the target. The distance and angle between two cameras were $410 \mathrm{~mm}$ and $25^{\circ}$, respectively, which is as recommended by GOM Ltd. [40]. A pair of 50-mm fixed focal length lenses, supplied by Nikon, UK, was employed for both cameras. These two cameras were triggered simultaneously by the signal generated from the infrared sensors and recorded, at their maximum rate of 39,000 frames per second, the deformation of the rear of the composite specimen. Two halogen lamps were employed to illuminate the rear surface of the CFRP specimens, which were only turned on a few seconds before each experiment was initiated. The 'GOM ARAMIS Professional' software [40] was employed for the data processing of the image series recorded from the high-speed cameras. For processing the measured DIC data, the images captured by the high-speed cameras employed a facet size of 19 pixels, with 15 pixels between each displacement point, following the recommendations for the optimum speckle size [40]. In order to monitor the full-field deformation of the specimens, the image size was selected as $256 \times 256$ pixels. After the gas-gun impact experiments has been completed, a portable 'Prisma 16:64 TOFD' ultrasonic C-scan device with a $5 \mathrm{MHz}$ probe, supplied by Sonatest Ltd. UK, as shown in Figs. 4 and 5, was employed to provide a further assessment of the damaged area.

For 'Set-up II' the aim was to study the ballistic response of the CF/PEEK and CF/epoxy composites subjected to a high-velocity impact by the relatively hard aluminium-alloy
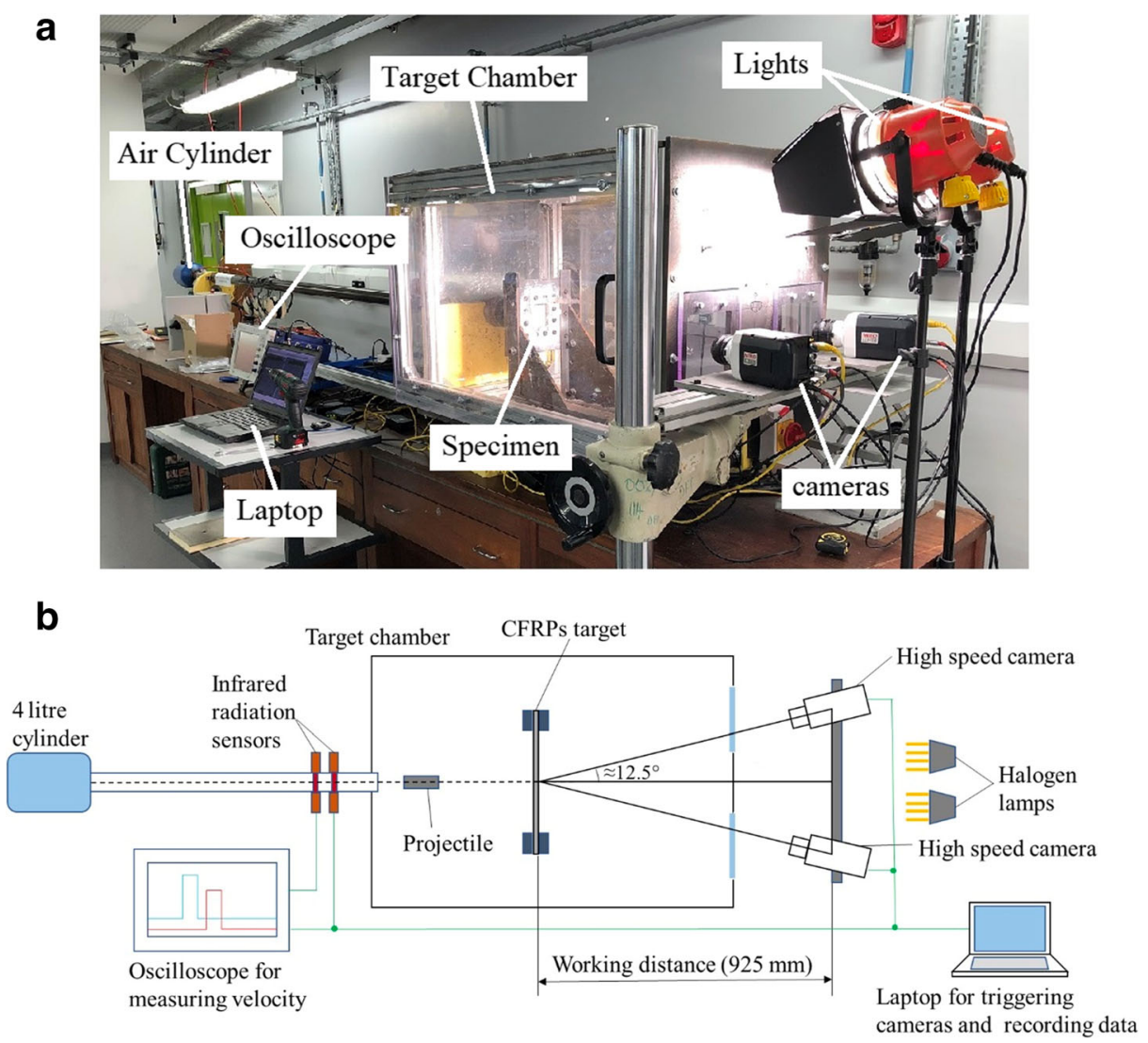

Fig. 4 Set-up I for the high-velocity soft-projectile impact: (a) photograph and (b) schematic (not to scale) 


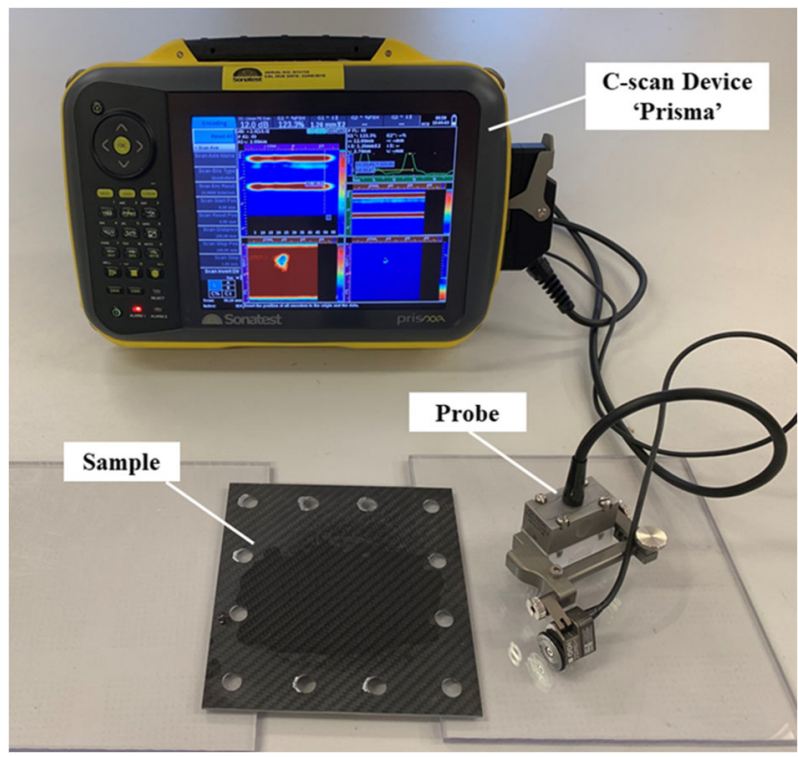

Fig. 5 Portable C-scan system

projectile. As shown in Fig. 6, two high-speed cameras were located at the side of the target chamber and recorded at their maximum rate of 39,000 frames per second. The kinetic energy absorbed during the impact could be determined via measuring the initial and residual velocities of the projectile. Two pairs of infrared sensors were also used to validate the initial velocity of the projectile as measured using the high-speed cameras.

\section{Experimental Results}

\subsection{The Soft Projectile Impact Tests}

\subsubsection{Impact Response}

The impact responses of the CFRP specimens were investigated over a range of impact velocities from 42 to $100 \mathrm{~m} . \mathrm{s}^{-1}$ using the soft-gelatine projectiles, and were therefore studied at different impact energy levels. Figures 7 and 8 show results for a soft-gelatine impact at $100 \mathrm{~m} . \mathrm{s}^{-1}$ on the CF/PEEK and the CF/epoxy specimens, respectively. Figure 7a shows the out-of-plane displacement maps obtained from the CF/PEEK specimen under soft impact loading, where both the loading and the unloading phases are included. The deformation profile across the middle section of the specimen is shown in Fig. 7b. This CF/PEEK specimen, which was subjected to an impact velocity of $100 \mathrm{~m} \cdot \mathrm{s}^{-1}$, exhibited a maximum out-of-plane displacement of approximately $3.7 \mathrm{~mm}$.

The out-of-plane displacement maps and deformation profiles of the CF/epoxy specimen, under a soft impact loading at an impact velocity of $100 \mathrm{~m} \cdot \mathrm{s}^{-1}$, are shown in Fig. $8 \mathrm{a}$ and b, respectively. In comparison to the DIC results of the CF/PEEK specimen, a $10 \%$ higher maximum out-of-plane displacement was determined for the CF/epoxy specimen. In addition, a slower rebound sequence for the CF/epoxy composite was found from the deformation 
a

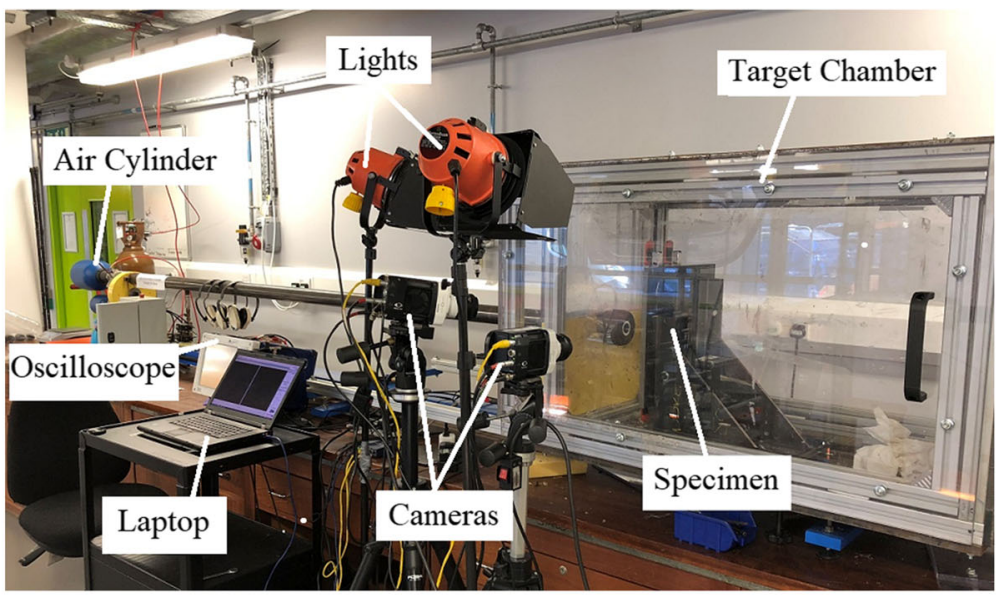

b

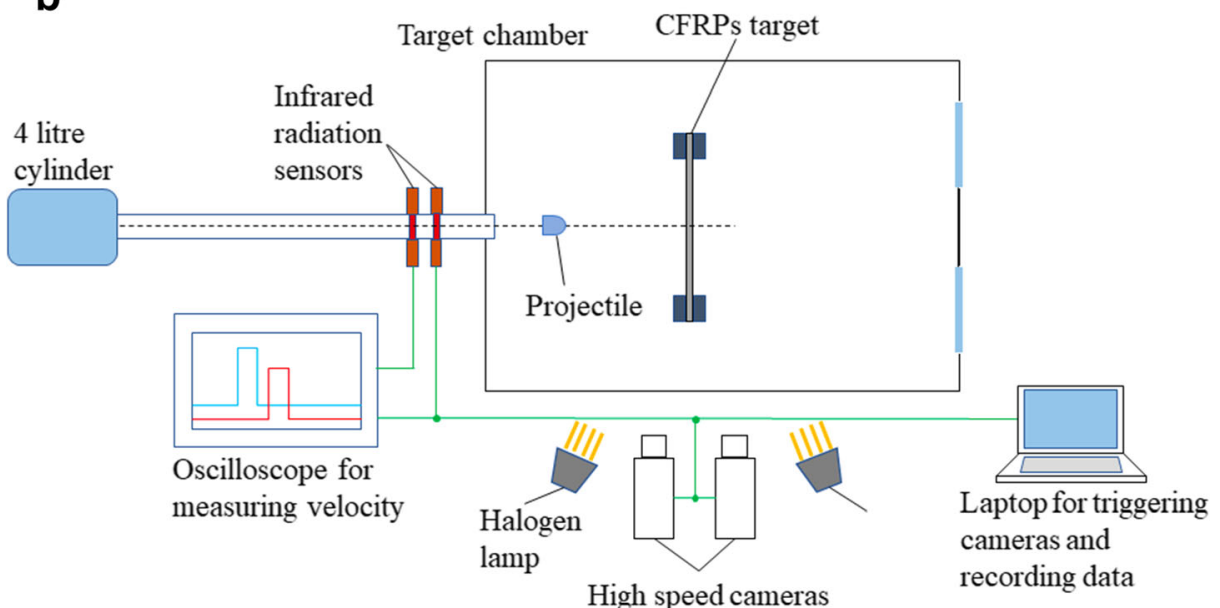

Fig. 6 Set-up II for the high-velocity hard-projectile impact: (a) photograph and (b) schematic

profiles for the unloading phase. These differences can be explained from the photographs of the rear surface and cross-section of the CF/epoxy specimen shown below, where significant impact damage was found in the central area of the specimen. The presence of damage, which was observed to arise from matrix cracking, delamination and fibre breakage, as discussed below, leads to a significant loss of the stiffness of the specimen. This, in turn, leads a higher maximum out-of-plane displacement and results in a slower rebound of the specimen in the unloading phase for the $\mathrm{CF} /$ epoxy composite, compared to the CF/PEEK composite.

The 3D DIC results of the maximum out-of-plane displacement of the specimens under four different impact velocities for both types of composites are summarised in Table 1 . In addition, the maximum out-of-plane displacement is plotted against the impact energy in Fig. 9. As may be seen, the values of the maximum out-of-plane displacements increase with increasing impact velocity. Also, at a similar impact velocity (i.e. at a similar impact energy level) the CF/epoxy composite undergoes a greater maximum out-of-plane displacement, compared to the CF/PEEK composite, and this difference is most striking at the highest impact velocity that was employed of $100 \mathrm{~m} \cdot \mathrm{s}^{-1}$. 

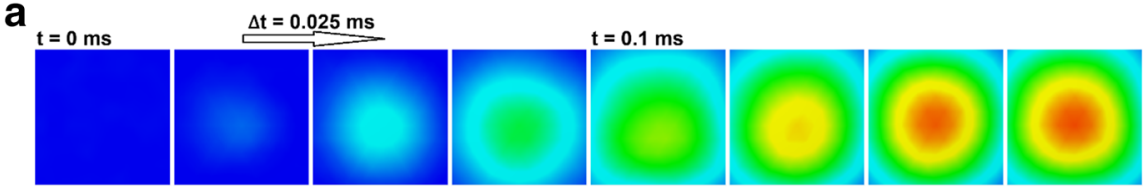

[mm]

$\mathrm{t}=0.2 \mathrm{~ms}$

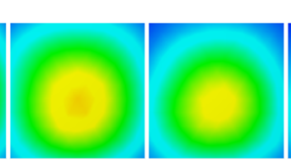

$\mathrm{t}=0.3 \mathrm{~ms}$
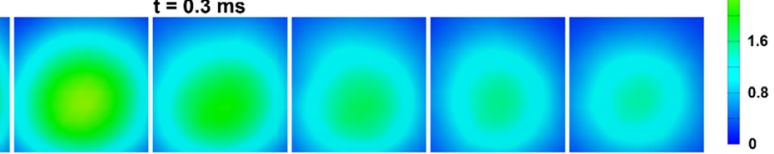

b
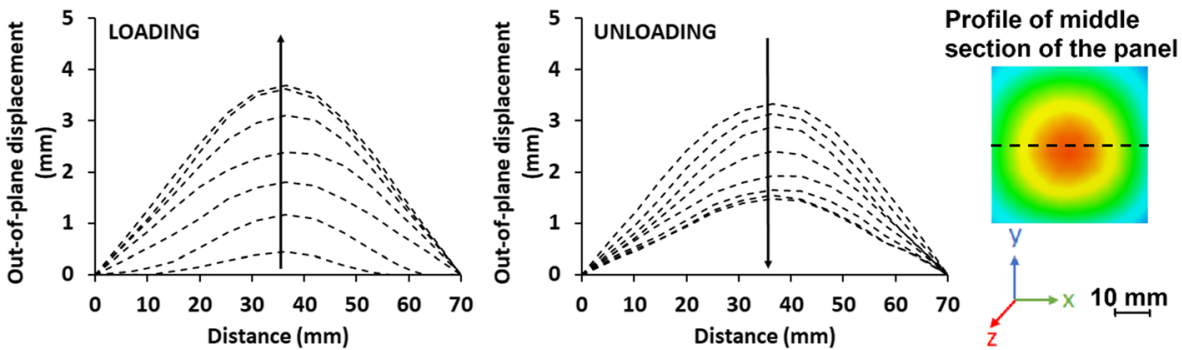

Fig. 7 Experimental results for the CF/PEEK panel impacted using a soft-gelatine projectile with a velocity of $100 \mathrm{~m} . \mathrm{s}^{-1}$ showing the (a) out-of-plane displacement maps and (b) out-of-plane displacement profile during the loading and unloading phases

a
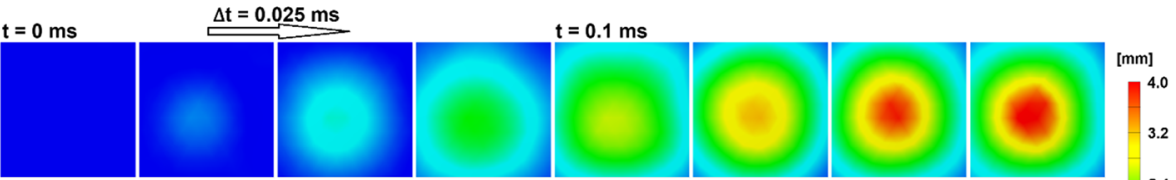

$\mathrm{t}=0.2 \mathrm{~ms}$

$\mathrm{t}=0.3 \mathrm{~ms}$
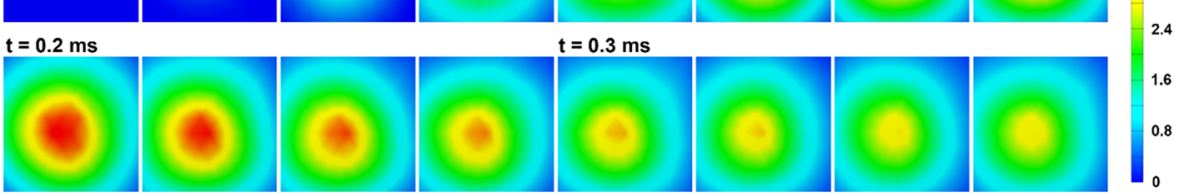

b
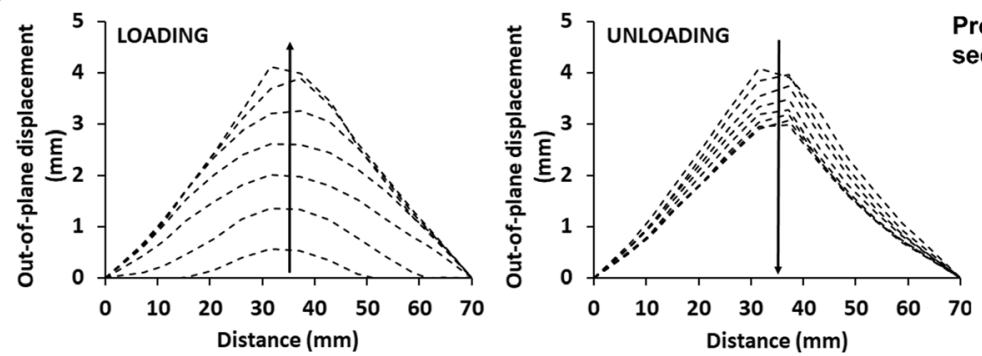

Profile of middle section of the panel

Fig. 8 Experimental results for the CF/epoxy panel impacted using a soft-gelatine projectile with a velocity of $100 \mathrm{~m} . \mathrm{s}^{-1}$ showing the (a) out-of-plane displacement maps and (b) out-of-plane displacement profile during the loading and unloading phases. (Inset picture, on right, shows a horizontal dash line where the profile section is taken) 
Table 1 Results of the high-velocity soft-gelatine projectile impact tests

\begin{tabular}{lllll}
\hline $\begin{array}{l}\text { Specimen } \\
\text { code }\end{array}$ & $\begin{array}{l}\text { Impact velocity* } \\
\left(\mathrm{m} \cdot \mathrm{s}^{-1}\right)\end{array}$ & $\begin{array}{l}\text { Projectile mass } \\
(\mathrm{g})\end{array}$ & $\begin{array}{l}\text { Impact energy* } \\
(\mathrm{J})\end{array}$ & $\begin{array}{l}\text { Maximum out-of-plane displacement } \\
(\mathrm{mm})\end{array}$ \\
\hline CF/PEEK_1 & 42.4 & 19.9 & 17.9 & 1.6 \\
CF/PEEK_2 & 58.1 & 19.9 & 33.6 & 2.2 \\
CF/PEEK_3 & 78.1 & 20.0 & 61.0 & 2.9 \\
CF/PEEK_4 & 100.0 & 19.8 & 99.0 & 3.7 \\
CF/epoxy_1 & 45.9 & 19.8 & 20.9 & 1.8 \\
CF/epoxy_2 & 57.5 & 20.0 & 33.1 & 2.3 \\
CF/epoxy_3 & 74.6 & 19.7 & 54.8 & 3.1 \\
CF/epoxy_4 & 100.0 & 19.9 & 99.5 & 4.2 \\
\hline
\end{tabular}

*Experimental error: $\pm 2.5 \%$ in impact velocity and $\pm 5 \%$ in impact energy

\subsubsection{Visual Inspections}

Visual inspections were performed on the rear surfaces of the CF/PEEK and the CF/epoxy specimens, as shown in Fig. 10a and b, respectively, for the different impact velocities used for the soft-gelatine projectile. Firstly, no visible damage was observed in any of the CF/PEEK specimens. Secondly, however, matrix cracking and fibre breakage were observed, at the highest impact velocity of $100 \mathrm{~m} \cdot \mathrm{s}^{-1}$ on the rear surface of the impacted CF/epoxy composite. The cross-sections of the CF/PEEK and CF/epoxy specimens impacted at $100 \mathrm{~m} \cdot \mathrm{s}^{-1}$ are shown in Fig. 11a and b, respectively. As may be seen, again no visible damage was observed in the $\mathrm{CF} / \mathrm{PEEK}$ composites, whereas different types of damage including matrix crack, delamination and fibre breakage were particularly observable in the CF/epoxy composite impacted at the highest test velocity of $100 \mathrm{~m} \cdot \mathrm{s}^{-1}$.

\subsubsection{C-Scan Results for the Composite Specimens}

A portable C-scan system was used to examine all the impacted specimens before and after the softprojectile impact experiments. The scans before impact showed that no damage was caused during

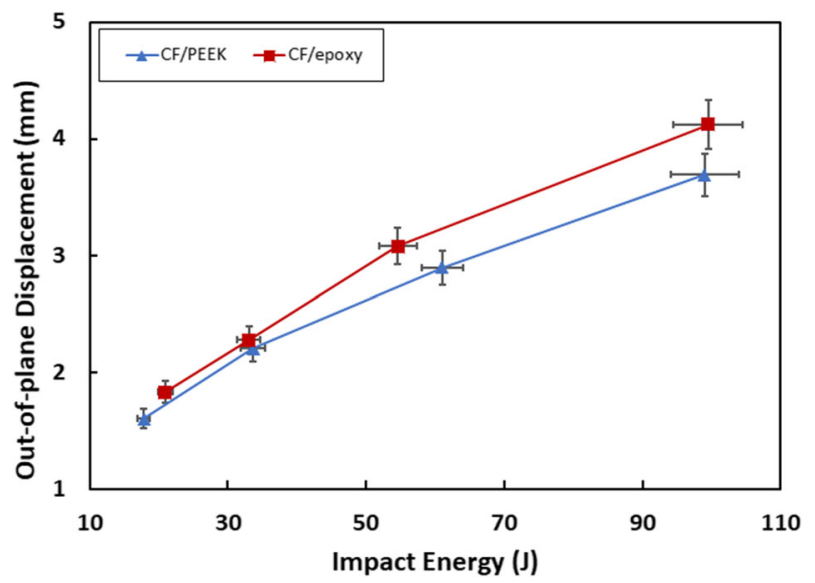

Fig. 9 Maximum out-of-plane displacement versus the impact energy for the CF/PEEK and CF/epoxy composites upon being impacted using soft-gelatine projectiles 

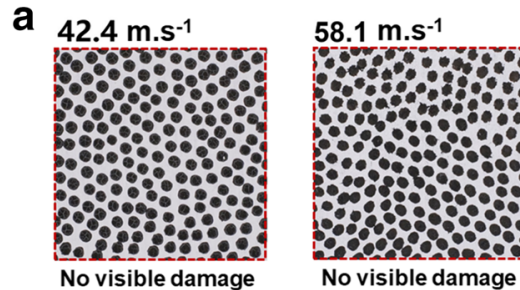

$78.1 \mathrm{~m} \cdot \mathrm{s}^{-1}$

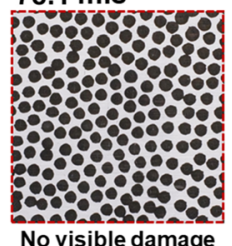

No visible damage

100 m.s ${ }^{-1}$
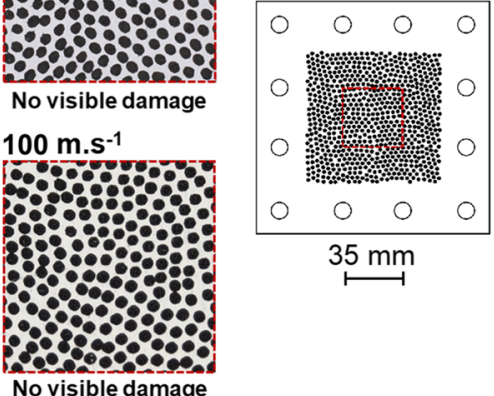

b

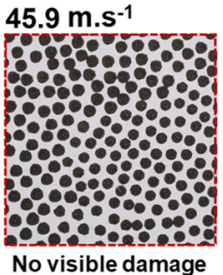

$57.5{\mathrm{~m} . \mathrm{s}^{-1}}^{-1}$

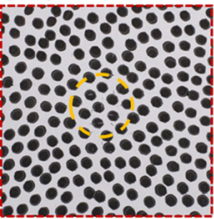

Slight paint cracking

$74.6 \mathrm{~m}^{-\mathrm{s}^{-1}}$

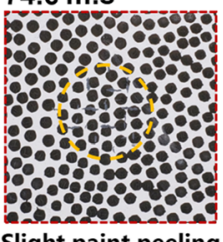

100 m.s ${ }^{-1}$
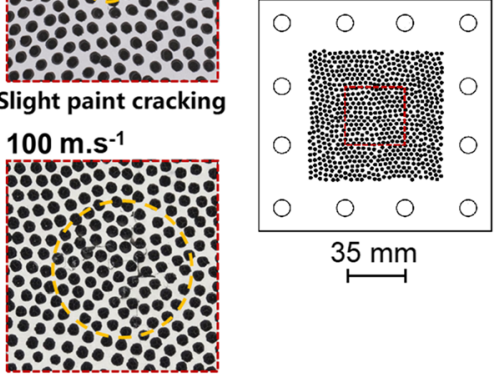

Slight paint peeling

Fibre breakage

Fig. 10 Visual inspection of the rear surface of the (a) CF/PEEK specimens and the (b) CF/epoxy specimens subjected to different impact velocities by the soft-gelatine projectile. (The area represented by the red square corresponds to the area shown on the schematic of the full specimen at the far right-hand side. The yellow circles indicate the extent of visible damage)

a

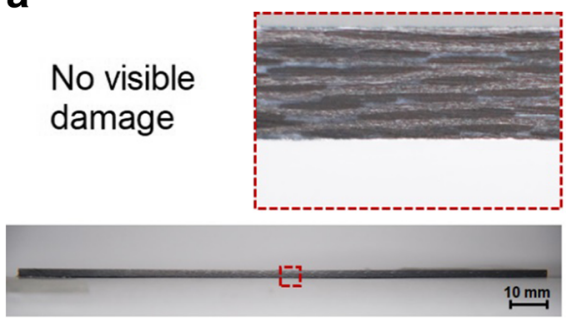

b

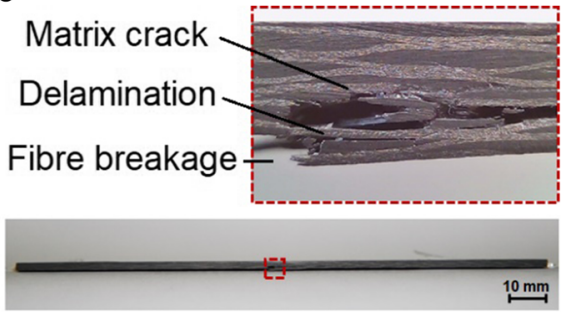

Fig. 11 Photographs of the cross-section of the mid-plane of the composite: (a) CF/PEEK and (b) CF/epoxy specimens impacted using a soft-gelatine projectile with an impact velocity of $100 \mathrm{~m} . \mathrm{s}^{-1}$ 
manufacture, transportation and storage. As noted above from Figs. 10 and 11, a visual inspection of the impacted specimens showed that significant damage was only observed in the CF/epoxy composite tested at the highest impact velocity, whilst no damage was ever observed in the $\mathrm{CF} /$ PEEK composite at any of the impact velocities employed. The relevant C-scan images in Fig. 12 show very clearly an area of delamination, in both the relatively low magnification and the higher magnification C-scan maps, for the CF/epoxy composite impacted at the highest velocity of $100 \mathrm{~m} \cdot \mathrm{s}^{-1}$. (These maps show delamination as a function of the depth through the thickness of the specimen, where the red colour is representative of the front (impacted) surface and blue colour is representative of the rear (non-impacted) surface of the specimen.) Thus, the ultrasonic C-scan maps reveal sub-surface damage only for the CF/epoxy composite, and then only significant damage when impacted at the highest velocity of $100 \mathrm{~m} \cdot \mathrm{s}^{-1}$. These findings are clearly in excellent agreement with the visual inspections discussed above. Therefore, it may again be concluded that the CF/PEEK laminates have a superior resistance to delamination when subjected to a soft impact at $100 \mathrm{~m} \cdot \mathrm{s}^{-1}$.

\subsection{The Hard-Projectile Impact Tests}

The perforation resistance and energy absorption of both the CF/PEEK and CF/epoxy specimens were studied when these composites were subjected to an impact by the relatively hard aluminium-alloy projectile over a range of impact velocities from 30 to $77 \mathrm{~m} . \mathrm{s}^{-1}$. The kinetic energy absorption, $\mathrm{E}_{\mathrm{a}}$, of the test specimen can be determined from:

$$
\mathrm{E}_{\mathrm{a}}=\frac{1}{2} \mathrm{mv}_{\mathrm{i}}^{2}-\frac{1}{2} \mathrm{mv}_{\mathrm{r}}^{2}
$$

where $\mathrm{m}$ is the weight of projectile, and $\mathrm{v}_{\mathrm{i}}$ and $\mathrm{v}_{\mathrm{r}}$ are the initial impact velocity and residual velocity (i.e. the exit or rebound velocity of the projectile), respectively. Three different impact velocities below and above the ballistic limit, which is the lowest velocity required for the projectile to penetrate consistently through the test specimen, were selected to investigate the

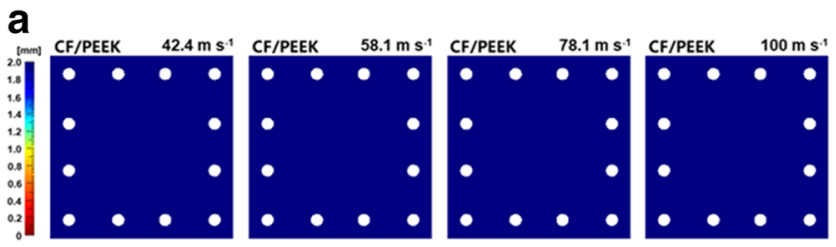

b

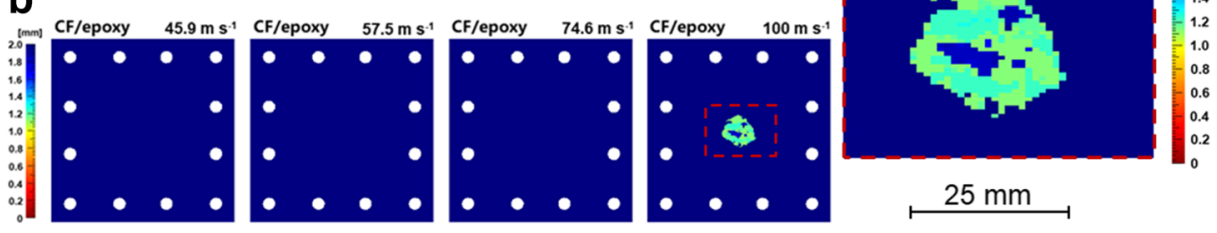

Fig. 12 Ultrasonic C-scan maps of the (a) CF/PEEK specimens and (b) CF/epoxy specimens subjected to impact velocities using the soft-gelatine projectile and (c) magnified $\mathrm{C}$-scan image of the CF/epoxy specimen impacted at the highest velocity of $100 \mathrm{~m} \cdot \mathrm{s}^{-1}$ 
relationship between the energy absorption and the damage suffered by the two types of composites.

The photographs obtained from the rear surface of the tested specimens are shown in Fig. 13. As may be seen, minor surface damage, with similar areal extents of the damage, can be observed from both types of specimens impacted at about $30 \mathrm{~m} . \mathrm{s}^{-1}$ (i.e. with an associated impact energy of 12-13 J). For an impact velocity above about $50 \mathrm{~m} . \mathrm{s}^{-1}$ (i.e. with an associated impact energy above about $40 \mathrm{~J}$ ) the CF/PEEK specimens perforated and exhibited damage areas which were slightly larger in size than the cross-sectional area of the projectile. In contrast, for impact energies above about $40 \mathrm{~J}$, the damage area was about three times larger in the perforated CF/epoxy specimens, compared to the CF/PEEK specimens. For both types of composite there was no significant further increase in the extent of the damage area when the impact velocity was raised to about $70 \mathrm{~m} \cdot \mathrm{s}^{-1}$.

The experimental results from using the hard aluminium-alloy projectile are summarised in Table 2. (It should be noted that in Table 2 a positive value in the residual velocity indicates that full perforation has occurred, whereas a negative value means that the projectile rebounded from the front surface of the specimen. Also, the damage area, $S_{d}$, of each specimen was determined, via a data processing programme, by measuring the number of pixels in the damage area compared to the total number in the specimen of known area.) The kinetic energy absorption and the damage area suffered by the composites are also plotted against the impact energy in Fig. 14. In addition, it should be noted that no visible deformation was observed in the aluminium-alloy projectiles post-impact.

\section{a $V_{\mathrm{i}}=\mathbf{3 0} \mathrm{m} \mathrm{s}^{-1}$}

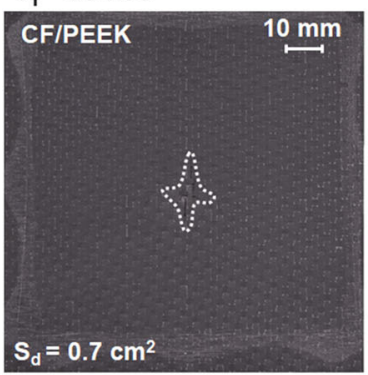

b $V_{\mathrm{i}}=29.1 \mathrm{~m} \mathrm{~s}^{-1}$

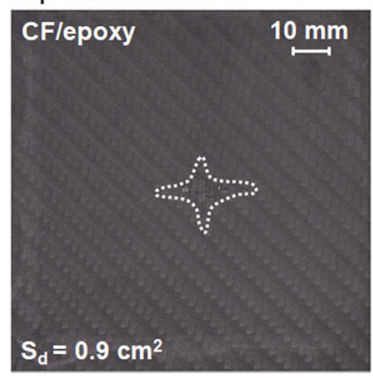

\section{$\mathrm{V}_{\mathrm{i}}=56.7 \mathrm{~m} \mathrm{~s}^{-1}$}

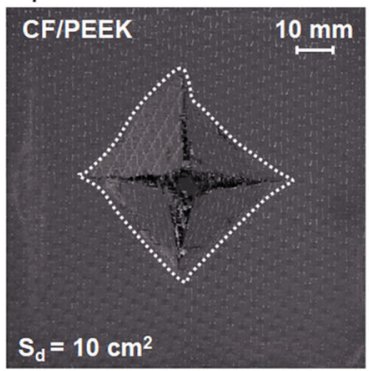

\section{$V_{i}=54.5 \mathrm{~m} \mathrm{~s}^{-1}$}

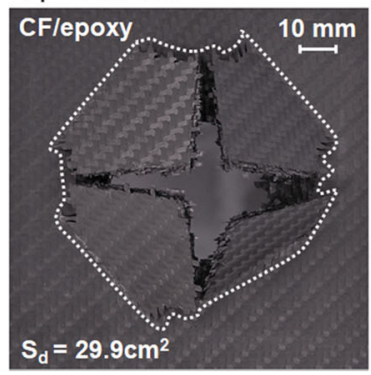

$\mathrm{V}_{\mathrm{i}}=76.8 \mathrm{~m} \mathrm{~s}^{-1}$

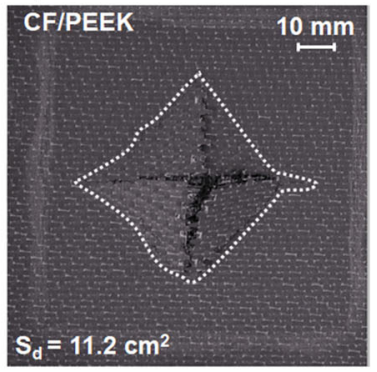

\section{$\mathrm{V}_{\mathrm{i}}=70.7 \mathrm{~m} \mathrm{~s}^{-1}$}

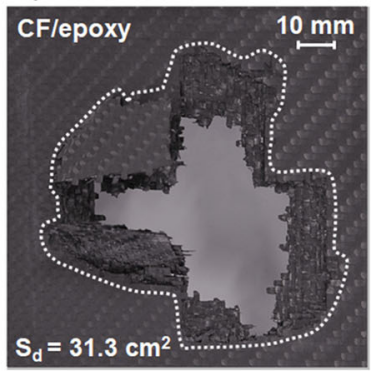

Fig. 13 Photographs of the rear surface of the (a) CF/PEEK and (b) CF/epoxy composites impacted using the hard aluminium-alloy projectile at various initial impact velocities. (The visible damage area, $\mathrm{S}_{\mathrm{d}}$, outlined in by the broken white line, was determined by measuring the number of pixels in the damage area compared to the total number in the specimen of known area) 
Table 2 Results of the high-velocity hard aluminium-alloy projectile impact tests

\begin{tabular}{lllllll}
\hline $\begin{array}{l}\text { Sample } \\
\text { code }\end{array}$ & $\begin{array}{l}\text { Initial velocity* } \\
\left(\mathrm{v}_{\mathrm{i}}\right)\left(\mathrm{m}_{\mathrm{s}} \mathrm{s}^{-1}\right)\end{array}$ & $\begin{array}{l}\text { Projectile } \\
\text { mass }(\mathrm{g})\end{array}$ & $\begin{array}{l}\text { Impact } \\
\text { energy* }(\mathrm{J})\end{array}$ & $\begin{array}{l}\text { Residual } \\
\text { velocity* }\left(\mathrm{v}_{\mathrm{r}}\right) \\
\left(\mathrm{m} . \mathrm{s}^{-1}\right)\end{array}$ & $\begin{array}{l}\text { Energy } \\
\text { absorption* }\left(\mathrm{E}_{\mathrm{a}}\right) \\
(\mathrm{J})\end{array}$ & $\begin{array}{l}\text { Damage area* } \\
\left(\mathrm{S}_{\mathrm{d}}\right)\left(\mathrm{cm}^{2}\right)\end{array}$ \\
\hline CF/PEEK_5 & 30.0 & 28.4 & 12.8 & -14.8 & 9.7 & 0.7 \\
CF/PEEK_6 & 56.7 & 28.2 & 45.3 & 23.2 & 37.7 & 10.0 \\
CF/PEEK_7 & 76.8 & 28.1 & 82.9 & 50.0 & 47.8 & 11.2 \\
CF/epoxy_5 & 29.1 & 28.1 & 11.9 & -15.5 & 8.6 & 0.9 \\
CF/epoxy_6 & 54.5 & 28.2 & 41.9 & 24.8 & 33.2 & 29.9 \\
CF/epoxy_7 & 70.7 & 28.3 & 70.7 & 47.8 & 38.4 & 31.3 \\
\hline
\end{tabular}

*Experimental error: $\pm 2 \%$ in velocities, $\pm 4 \%$ in impact energy and $\pm 5 \%$ in damage area

In Fig. 14 it can be seen that, as the impact energy is increased, then both the kinetic energy absorption and the damage area increase. Once perforation occurs at an impact energy of about $40 \mathrm{~J}$, and beyond, there is, however, a far smaller increase on the energy absorption and damage area as the impact velocity is further increased. This phenomenon has previously been observed in the impact behaviour and failure mechanisms of composites when they are perforated by an impacting projectile [31]. Now, the damage is considered to arise from compressive stress waves which are generated and transmitted through the volume of the composite material after impact. These waves are reflected when reaching the rear layer of the composite panel to form tensile waves which now act upon the neighbouring ply interfaces and can initiate delamination, and so lead to extensive interlaminar failure. Also, shear failures occur when the projectile starts to penetrate the uppermost layers of the composites. Subsequently, when the projectile reaches the delaminated layers, these layers can slide over each other and ultimately fail completely due to tensile failure. It is for these reasons that a larger damage area is found on the rear surface. Now, many researchers [31, 41, 42] have indeed reported the phenomenon that the damage area in the composite increases relatively rapidly with an initial increase in the impact velocity up to the ballistic limit velocity, and then the damage area remains relatively constant in extent beyond this velocity. As was indeed observed in the present high-velocity tests using the hard aluminium-alloy projectile.

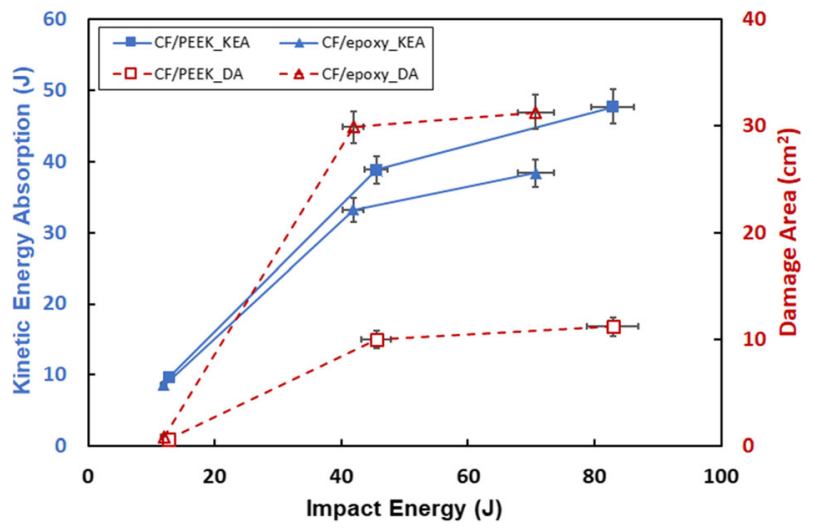

Fig. 14 Comparison of the kinetic energy absorption (KEA) and damage area (DA) versus the impact energy for the $\mathrm{CF} / \mathrm{PEEK}$ and $\mathrm{CF} /$ epoxy composites impacted using the hard aluminium-alloy projectile at different velocities. (Note: perforation of the composites occurred at, and beyond, an energy level of about $40 \mathrm{~J}$ ) 


\section{Modelling Studies}

It is important to note that, at similar impact energy levels, the aluminium-alloy-impacted composites, see Fig. 13 and Table 2, exhibited a far more severe degree of damage than that seen in the gelatine-impacted test specimens, see Table 1 and Fig. 10. Thus, this comparison shows that the composites are far more vulnerable to the projectile with the relatively high hardness, i.e. the aluminium-alloy projectile. Now, due its relatively low hardness, the softgelatine projectile will tend to undergo considerable deformation after it has made initial contact with the target test specimen, which will lead to flow of the gelatine projectile. Therefore, the deformed gelatine projectile has a larger contact area on the impacted face of the composite. This will reduce the average contact pressure caused by the impact loading, given by:

$$
\mathrm{P}_{\mathrm{c}}=\frac{\mathrm{F}}{\mathrm{A}_{\mathrm{c}}}
$$

where $\mathrm{F}$ is the impact load, and $\mathrm{P}_{\mathrm{c}}$ and $\mathrm{A}_{\mathrm{c}}$ are the average contact pressure and contact area between the projectile and specimen, respectively. Now, the out-of-plane displacement on the rear-face of the composite specimen will tend to decrease with the increase in the contact area. Compared with the soft-gelatine projectile, the hard aluminium-alloy projectile deformed negligibly and the contact area was much smaller during the impact event. This leads to a higher average contact pressure and this, in turn, leads to more localised damage in the composite specimens when they are impacted by the relatively hard aluminium-alloy projectile, compared with the relatively soft-gelatine projectile.

To further investigate and confirm this phenomenon, a FE model was developed in Abaqus to simulate the soft- and hard-impact on the composites so as to obtain the contact stresses between the projectiles and the composite specimens. In the model, the soft-gelatine projectile was modelled using the SPH method. The Mie-Grüneisen linear equation of state [43] was employed to define the linear relationship between the shock-wave velocity, $U_{s}$, versus the impact velocity, $U_{p}$, of the projectile. This relationship is therefore given by:

$$
\mathrm{U}_{\mathrm{s}}=\mathrm{c}_{0}+\mathrm{sU}_{\mathrm{p}}
$$

where the fitting coefficient, $s$, is the slope of the linear relationship between $U_{s}$ and $U_{p}$. The coefficient $\mathrm{c}_{0}$ is the reference speed of sound in the soft-gelatine projectile. Considering the term $U_{p}$, the impact velocity of the projectile was assigned to be the value of $U_{p}$ for all the 8node linear-brick (C3D8R) elements when the FE model was first started. When the simulation started to run, these elements for the soft-gelatine projectile were converted to continuum particle (PC3D) elements and the value of $U_{p}$ assigned to the particle elements was then continually updated based upon the loading conditions on the particles after the initial contact. In contrast, as mentioned above, there was no obvious plastic deformation of the hard aluminium-alloy projectiles during the experiments. Therefore, the aluminium-alloy projectile was simply modelled as an elastic body. The input parameters required for the numerical modelling of the soft-gelatine and hard aluminium-alloy projectiles are shown in Table 3.

The main model for predicting the initiation of damage in 'Abaqus/Explicit 2017' software is a sub-routine which is based upon the Hashin methodology [43, 47], and the full details are given in [48]. The main aspects to note are that the general forms of the damage criteria in Hashin's approach are employed to model the initiation of four different types of damage, as given in [47]: 
Table 3 Properties required for modelling the projectiles [44 46]

\begin{tabular}{lll}
\hline Property & Soft-gelatine & Hard aluminium-alloy \\
\hline Reference density & $1.06 \mathrm{~g} / \mathrm{cm}^{3}$ & $2.81 \mathrm{~g} / \mathrm{cm}^{3}$ \\
Modulus & $\mathrm{N} / \mathrm{A}$ & $71.7 \mathrm{GPa}$ \\
Poisson's ratio & $\mathrm{N} / \mathrm{A}$ & 0.33 \\
Dynamic viscosity & $1 \times 10^{-6} \mathrm{MPa} \cdot \mathrm{s}$ & $\mathrm{N} / \mathrm{A}$ \\
Reference speed of sound & $\mathrm{c}_{0}=1.45 \times 10^{6} \mathrm{~mm} / \mathrm{s}$ & N/A \\
Slope of the Us versus Up curve & $\mathrm{s}=1.87$ & N/A \\
Grüneisen ratio & $\Gamma=1.09$ & N/A \\
\hline
\end{tabular}

$$
\begin{aligned}
& \text { Tensile fibre failure }\left(\hat{\sigma}_{11} \geq 0\right): \mathrm{F}_{\mathrm{f}}^{\mathrm{t}}=\left(\frac{\hat{\sigma}_{11}}{\mathrm{X}^{\mathrm{T}}}\right)^{2} \\
& \text { Compressive fibre failure }\left(\hat{\sigma}_{11}<0\right): \mathrm{F}_{\mathrm{f}}^{\mathrm{c}}=\left(\frac{\hat{\sigma}_{11}}{\mathrm{X}^{\mathrm{C}}}\right)^{2} \\
& \text { Tensile matrix failure }\left(\hat{\sigma}_{22} \geq 0\right): \mathrm{F}_{\mathrm{m}}^{\mathrm{t}}=\left(\frac{\hat{\sigma}_{22}}{\mathrm{Y}^{\mathrm{T}}}\right)^{2} \\
& \text { Compressive matrix failure }\left(\hat{\sigma}_{22}<0\right): \mathrm{F}_{\mathrm{m}}^{\mathrm{c}} \\
& =\left(\frac{\hat{\sigma}_{22}}{2 \mathrm{~S}^{\mathrm{T}}}\right)^{2}+\left[\left(\frac{\mathrm{Y}^{\mathrm{C}}}{2 \mathrm{~S}^{\mathrm{T}}}\right)^{2}-1\right] \frac{\sigma_{22}}{\mathrm{Y}^{\mathrm{C}}}+\left(\frac{\hat{\tau}_{12}}{\mathrm{~S}^{\mathrm{L}}}\right)^{2}
\end{aligned}
$$

In the above equations, the indices on the terms, $\mathrm{F}_{\mathrm{f}}^{\mathrm{t}}, \mathrm{F}_{\mathrm{f}}^{\mathrm{c}}, \mathrm{F}_{\mathrm{m}}^{\mathrm{t}}$ and $\mathrm{F}_{\mathrm{m}}^{\mathrm{c}}$, represent the four types of damage of tensile fibre failure, compressive fibre failure, tensile matrix failure and compressive matrix failure, respectively. The parameters, $\mathrm{X}^{\mathrm{T}}$ and $\mathrm{X}^{\mathrm{C}}$ denote the tensile and compressive strengths in the longitudinal-fibre direction, respectively. The terms $\mathrm{Y}^{\mathrm{T}}$ and $\mathrm{Y}^{\mathrm{C}}$ are the tensile and compressive strengths in the transverse-fibre direction, respectively; $\mathrm{S}^{\mathrm{L}}$ and $\mathrm{S}^{\mathrm{T}}=\mathrm{Y}^{\mathrm{C}} / 2$ denote the shear strengths in the longitudinal and transverse directions to the fibres, respectively; and $\sigma_{11}, \sigma_{22}$ and $\tau_{12}$ are the components of the effective stress tensor, $\sigma$, that are used to evaluate the criteria.

To calculate and compare the values of the contact pressures caused by the soft-gelatine projectiles and hard aluminium-alloy projectiles, the impact behaviour of the CF/PEEK composite target was modelled. The relevant material properties of the $\mathrm{CF} / \mathrm{PEEK}$ composites required for the modelling studies may be found from the literature [11, 12, 15, 48-54] and are given in Table 4.

As stated above, full details of the modelling studies are given in [48], but briefly in the FE model the soft-gelatine projectile was first modelled using 8-node linear-brick (C3D8R) elements, which were then converted to continuum particle (PC3D) elements, see Fig. 15a. The characteristic length for the PC3D elements was $0.5 \mathrm{~mm}$, which was equivalent to half of the element size that was used for modelling the gelatine projectile with the CSD8R elements. 
Table 4 The input parameters for the composite damage model [11, 12, 15, 48-54]

\begin{tabular}{ll}
\hline Property & Values \\
\hline Moduli $(\mathrm{GPa})$ & $\mathrm{E}_{11}=127 ; \mathrm{E}_{22}=10.3 ; \mathrm{G}_{12}=5.7$ \\
Poisson's ratio & $\mathrm{V}_{12}=0.3$ \\
Strength values $(\mathrm{MPa})$ & $\mathrm{X}^{\mathrm{T}}=2070 ; \mathrm{Y}^{\mathrm{T}}=85 ; \mathrm{X}^{\mathrm{C}}=1360 ; \mathrm{Y}^{\mathrm{C}}=276 ;$ \\
& $\mathrm{S}^{\mathrm{L}}=\mathrm{S}^{\mathrm{T}}=186 ;$ \\
Ply fracture energies $\left(\mathrm{kJ} / \mathrm{m}^{2}\right)$ & $\left.\mathrm{G}_{\mathrm{Ic}}\right|_{\mathrm{ft}}=218 ; \mathrm{G}_{\mathrm{Ic}}\left|\mathrm{fc}=104 ; \mathrm{G}_{\mathrm{Ic}}\right| \mathrm{mt}=1.7 ;\left.\mathrm{G}_{\mathrm{Ic}}\right|_{\mathrm{mc}}=2.0$ \\
Interlaminar fracture energies* & $\mathrm{G}_{\mathrm{Ic}}=1.7 ; \mathrm{kJ}_{\mathrm{IIc}}=2.0$ \\
B-K coefficient* & $\eta_{\mathrm{BK}}=1.09$ \\
Cohesive strengths $(\mathrm{MPa})$ & $\mathrm{t}_{33}^{0}=43 ; \mathrm{t}_{31}^{0}=\mathrm{t}_{32}^{0}=50$ \\
Cohesive stiffness $(\mathrm{N} / \mathrm{mm})$ & $\mathrm{k}=6.4 \times 10^{5}$ \\
\hline
\end{tabular}

*These properties are for interlaminar failure between two of the $\left[0^{\circ}-90^{\circ}\right]$ woven-fibre plies

$\mathrm{k}$ is the cohesive stiffness in the interlaminar bilinear damage model

$\mathrm{t}_{\mathrm{i}}^{0}(\mathrm{i}=33,31,32)$ are the normal and shear cohesive strengths in the interlaminar bilinear damage model

$\mathrm{G}_{\mathrm{Ic}}$ and $\mathrm{G}_{\mathrm{IIc}}$ are the Mode I and Mode II interlaminar fracture energies between two $\left[0^{\circ}-90^{\circ}\right]$ woven-fibre composite plies

$\left.\mathrm{G}_{\mathrm{Ic}}\right|_{\mathrm{ft}}$ and $\left.\mathrm{G}_{\mathrm{Ic}}\right|_{\mathrm{fc}}$ are the tensile and compressive ply fracture energies of the unidirectional-fibre sub-plies in the longitudinal fibre-direction

$\left.\mathrm{G}_{\mathrm{Ic}}\right|_{\mathrm{mt}}$ and $\left.\mathrm{G}_{\mathrm{Ic}}\right|_{\mathrm{mc}}$ are the tensile and compressive ply fracture energies of the unidirectional-fibre sub-plies in the transverse to fibre-direction

$\eta_{\mathrm{BK}}$ is the Benzeggagh-Kenane (B-K) coefficient for failure

The total mass of the projectile was equally distributed between all the 8-node linear-brick (C3D8R) elements or all the continuum particle (PC3D) elements. The hard aluminium-alloy projectile was defined as an elastic body and modelled using the C3D8R elements with an element size of $1 \mathrm{~mm} \times 1 \mathrm{~mm} \times 1 \mathrm{~mm}$, see Fig. $15 \mathrm{~b}$.

For comparison, the impact energy was set as $40 \mathrm{~J}$ for the simulation of both the gelatine projectile and the aluminium-alloy projectile impact events and the reaction force versus time history was obtained from the FE models, see Fig. 16a. It can be seen that the aluminum-alloy impacted CF/PEEK composite exhibited a significantly higher reaction force than the gelatineimpacted $\mathrm{CF} / \mathrm{PEEK}$ composite. The maximum reaction forces associated with the soft-gelatine
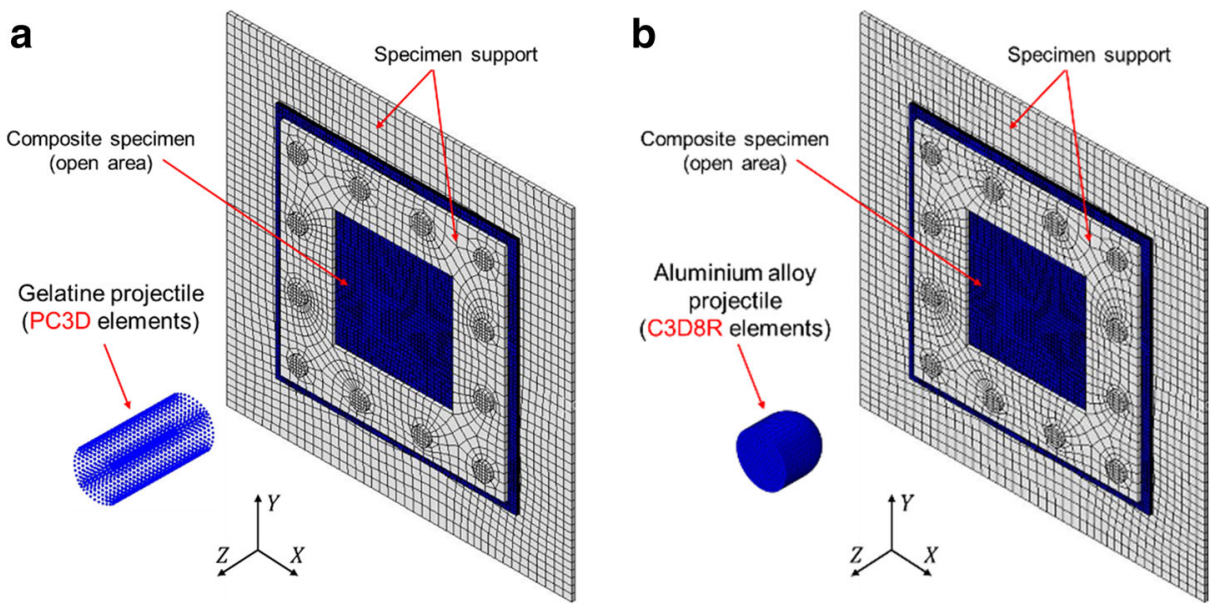

Fig. 15 The FE model for simulating (a) the soft-gelatine particle (PC3D) impact and (b) the hard aluminiumalloy projectile impact on the composites 

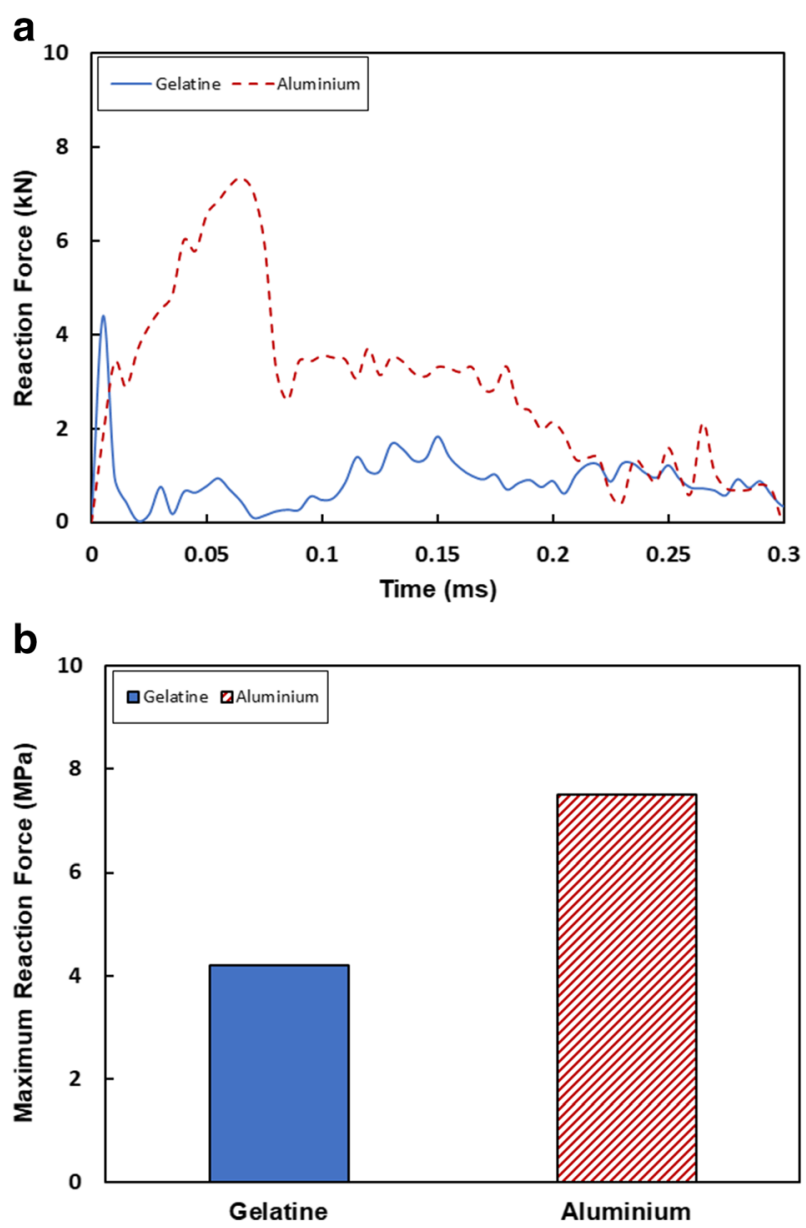

Fig. 16 Numerical FE modelling predictions for an impact energy level of $40 \mathrm{~J}$ under a soft-gelatine impact event and a hard aluminium-alloy impact event on the CF/PEEK composites: (a) the reaction force versus time history and (b) the maximum reaction force

and the hard aluminium-alloy impacts on the CF/PEEK composites were calculated to be 4.4 $\mathrm{kN}$ and $7.4 \mathrm{kN}$, respectively, see Fig. 16b. These predicted values reveal that the aluminiumalloy projectile with a relatively high hardness does indeed give a significantly higher reaction force during the impact event, compared with that induced by impact of the soft-gelatine projectile. This clearly confirms the reasons given above for why significantly greater damage is created in the composites when impacted by the hard aluminium-alloy projectile, compared with the soft-gelatine projectile.

\section{Conclusions}

In the present study, the impact performance of woven-fabric carbon-fibre (CF) composites based upon both thermoplastic- and thermoset-matrix polymers under high-velocity impact loading have been studied by conducting gas-gun experiments at impact velocities of up to 
$100 \mathrm{~m} \cdot \mathrm{s}^{-1}$. The thermoplastic matrix was poly(ether-ether ketone) (PEEK) and the thermoset matrix was a non-toughened epoxy (EP). The carbon-fibre reinforced-polymers (CFRPs) were impacted using a soft- (i.e. gelatine) or a hard- (i.e. aluminium-alloy) projectile to simulate either a soft bird-strike or a hard foreign-body impact (e.g. runway debris), respectively, on composites typically employed in the fuselage and wing structures of civil aircraft.

The main conclusions are:

- For the high-velocity soft-gelatine impact tests, the 3D Digital Image Correlation (DIC) technique was successfully employed to determine the out-of-plane displacements of the woven-fabric composites specimens at different impact velocities, and hence different impact energy levels. The woven-fabric CF/PEEK composites, with the same lay-up and thickness and approximately the same density as the CF/epoxy composites, exhibited a reduced maximum out-of-plane deformation compared to the CF/epoxy composites. Indeed, fibre and matrix damage on the rear of the specimen, and sub-surface damage, indicated that significant damage was only observed in the CF/epoxy composite, and then only at the highest velocity of $100 \mathrm{~m} \cdot \mathrm{s}^{-1}$.

- Delamination damage was indeed observed in the C-scan map of the CF/epoxy composite impacted at the highest velocity of $100 \mathrm{~m} \cdot \mathrm{s}^{-1}$. By contrast, no areas of delamination were found in any $\mathrm{C}$-scan maps of the $\mathrm{CF} / \mathrm{PEEK}$ composite specimens. It was therefore concluded that the $\mathrm{CF} / \mathrm{PEEK}$ composite has a superior damage resistance compared to the equivalent $\mathrm{CF} /$ epoxy composite when subjected to a high-velocity impact by the softgelatine projectile, which simulates a bird-strike.

- For the high-velocity impact tests using a hard aluminium-alloy projectile, with a hemispherical head, to simulate runway debris, superior impact resistance was again observed in the CF/PEEK composite, compared to the CF/epoxy composite. The efficiency of kinetic energy absorption decreases with the increasing impact velocity from about 30 to $75 \mathrm{~m} . \mathrm{s}^{-1}$. The CF/PEEK composite was more efficient in absorbing kinetic energy for these velocities and the resulting damage area was less extensive than for the CF/epoxy composite.

- As to be expected, at similar impact energy levels, the composites are more vulnerable to the relatively hard aluminium-alloy projectile compared with the soft-gelatine projectile. This is attributed to the higher contact pressures, and their localisation, associated with the aluminium-alloy projectile. These suggestions were indeed confirmed by the predictions from a numerical modelling study.

- It is important to note that the CF/PEEK composite showed improved impact performance both when struck by the relatively hard aluminium-alloy projectile (to simulate runway debris) or by the soft-gelatine projectiles (to simulate bird-strike), compared to the $\mathrm{CF} /$ epoxy composite.

Acknowledgements The strong support from the Aviation Industry Corporation of China (AVIC), the First Aircraft Institute (FAI) and the Manufacturing Technology Institute (MTI) for funding this research is much appreciated. The research was performed at the AVIC Centre for Structural Design and Manufacture at Imperial College London.

Open Access This article is distributed under the terms of the Creative Commons Attribution 4.0 International License (http://creativecommons.org/licenses/by/4.0/), which permits unrestricted use, distribution, and reproduction in any medium, provided you give appropriate credit to the original author(s) and the source, provide a link to the Creative Commons license, and indicate if changes were made. 


\section{References}

1. Hawk, J.: The Boeing 787 Dreamliner: more than an airplane. In: Aircraft Noise and Emissions Reduction Symposium, Monterey, USA (2005)

2. Hellard, G.: Composites in Airbus: a long story of innovations and experiences. In: Airbus Global Investor Forum, Seville, Spain (2008)

3. Foster, D.S., Applman, H.S.: Aviation Hail Problem (WMO-No. 109. TP. 47). World Meteorological Organization, Geneva, Switzerland (1961)

4. Herricks, E., Mayer, D., Majumdar, S.: Foreign Object Debris Characterization at a Large International Airport, Springfield, USA (2015)

5. Alves, M., Chaves, C.E., Birch, R.S.: Impact on aircraft. 17th. Int Congr Mech Eng. 1-8 (2003)

6. Dolbeer, R., Beiger, J.: M. Wildlife strikes to civil aircraft in the United States 1990-2017. Federal Aviation Administration. In: USA (2019)

7. Bennett, D.L. Debris hazards at airports. Federal Aviation Adiministration, USA; 1996

8. Dorey, G., Bishop, S.M., Curtis, P.T.: On the impact performance of carbon fibre laminates with epoxy and PEEK matrices. Compos. Sci. Technol. 23, 221-237 (1985)

9. Shyr, T.W., Pan, Y.H.: Impact resistance and damage characteristics of composite laminates. Compos. Struct. 62, 193-203 (2003)

10. $\mathrm{Xu}, \mathrm{S}$., Chen, P.H.: Prediction of low velocity impact damage in carbon/epoxy laminates. Procedia Eng. 67, 489-496 (2013)

11. Liu, H., Falzon, B.G., Tan, W.: Experimental and numerical studies on the impact response of damagetolerant hybrid unidirectional/woven carbon-fibre reinforced composite laminates. Compos Part B Eng. 136, 101-118 (2018)

12. Liu, H., Falzon, B.G., Tan, W.: Predicting the compression-after-impact (CAI) strength of damage-tolerant hybrid unidirectional/woven carbon-fibre reinforced composite laminates. Compos Part A Appl Sci Manuf. 105, 189-202 (2018)

13. Ghasemi Nejhad, M.N., Parvizi-Majidi, A.: Impact behaviour and damage tolerance of woven carbon fibrereinforced thermoplastic composites. Composites. 21(2), 155-168 (1990)

14. Ong, C.L., Liou, Y.Y.: Characterization of mechanical behaviors of advanced thermoplastic composite after impact. Acta Astronaut. 29, 99-108 (1993)

15. Liu, H., Falzon, B.G., Li, S., Tan, W., Liu, J., Chai, H., Blackman, B.R.K., Dear, J.P.: Compressive failure of woven fabric reinforced thermoplastic composites with an open-hole: an experimental and numerical study. Compos. Struct. 213, 108-117 (2019)

16. Cox, B.N., Dadkhah, M.S., Morris, W.L., Flintoff, J.G.: Failure mechanisms of 3D woven composites in tension, compression, and bending. Acta Metall. Mater. 42, 3967-3984 (1994)

17. Turner, P., Liu, T., Zeng, X., Brown, K.: Three-dimensional woven carbon fibre polymer composite beams and plates under ballistic impact. Compos. Struct. 185, 483-495 (2018)

18. Peters, S.T.: Handbook of Composites. Springer, USA (1998)

19. Kashtalyan, M.: Introduction to Composite Materials Design, vol. 115. The Aeronautical Journal. Cambridge University Press, UK (2011)

20. Newaz, G.M.: Advances in Thermoplastic Matrix Composite Materials. ASTM International, USA (1989)

21. Cogswell, F.N.: Thermoplastic Aromatic Polymer Composites: a Study of the Structure, Processing and Properties of Carbon Fibre Reinforced Polyetheretherketone and Related Materials. Elsevier, UK (2013)

22. Long, A.C.: Composites Forming Technologies. Elsevier, UK (2014)

23. Vieille, B., Casado, V.M., Bouvet, C.: About the impact behavior of woven-ply carbon fiber-reinforced thermoplastic- and thermosetting-composites: a comparative study. Compos. Struct. 101, 9-21 (2013)

24. Sjoblom, P.O., Hartness, J.T., Cordell, T.M.: On low-velocity impact testing of composite materials. J. Compos. Mater. 22, 30-52 (1988)

25. Morton, J., Godwin, E.W.: Impact response of tough carbon fibre composites. Compos. Struct. 13, 1-19 (1989)

26. Ishikawa, T., Sugimoto, S., Matsushima, M., Hayashi, Y.: Some experimental findings in compression-afterimpact (CAI) tests of CF/PEEK (APC-2) and conventional CF/epoxy flat plates. Compos. Sci. Technol. 55, 349-363 (1995)

27. Cantwell, W.J., Morton, J.: Comparison of the low and high velocity impact response of CFRP. Composites. 20, 545-551 (1989)

28. Morita, H., Adachi, T., Tateishi, Y., Matsumot, H.: Characterization of impact damage resistance of cf/peek and cf/toughened epoxy laminates under low and high velocity impact tests. J. Reinf. Plast. Compos. 16, 131-143 (1997)

29. Cantwell, W.J., Morton, J.: Detection of impact damage in CFRP laminates. Compos. Struct. 3, 241-257 (1985) 
30. Cantwell, W.J., Curtis, P.T., Morton, J.: An assessment of the impact performance of CFRP reinforced with high-strain carbon fibres. Compos. Sci. Technol. 25(2), 133-148 (1986)

31. Cantwell, W.J., Morton, J.: Impact perforation of carbon fibre reinforced plastic. Compos. Sci. Technol. 38, 119-141 (1990)

32. Cantwell, W.J., Morton, J.: The impact resistance of composite materials - a review. Composites. 22, 347362 (1991)

33. Wilbeck, J.S.: Impact Behavior of Low Strength Projectiles (AFML-TR-77-134). Air Force Materials Lab, Dayton, USA (1978)

34. Wilbeck, J.S. Bird impact forces and pressures. Air Force Flight Dyn Lab Tech Rep AFFDL-TR-77-60. 1978

35. Wilbeck, J.S., Rand, J.L.: The development of a substitute bird model. J Eng Power. 103(4), 725-730 (1981)

36. Mohagheghian, I., Wang, Y., Zhou, J., Yu, L., Guo, X., Yan, Y., Charalambides, M.N., Dear, J.P.: Deformation and damage mechanisms of laminated glass windows subjected to high velocity soft impact. Int. J. Solids Struct. 109, 46-62 (2017)

37. Zhou, J., Liu, J., Zhang, X., Yan, Y., Jiang, L., Mohagheghian, I., Dear, J.P., Charalambides, M.N.: Experimental and numerical investigation of high velocity soft impact loading on aircraft materials. Aerosp. Sci. Technol. 90, 44-58 (2019)

38. Nishikawa, M., Hemmi, K., Takeda, N.: Finite-element simulation for modeling composite plates subjected to soft-body, high-velocity impact for application to bird-strike problem of composite fan blades. Compos. Struct. 93, 1416-1423 (2011)

39. Liu, J., Li, Y., Gao, X.: Bird strike on a flat plate: experiments and numerical simulations. Int J Impact Eng. 70, 21-37 (2014)

40. GOM mbH. Aramis User Manual. 1301_01_EN, pp. 1-57, Braunschweig, Germany (2016)

41. López-Puente, J., Zaera, R., Navarro, C.: The effect of low temperatures on the intermediate and high velocity impact response of CFRPs. Compos Part B Eng. 33, 559-566 (2002)

42. Wang, B., Xiong, J., Wang, X., Ma, L., Zhang, G.Q., Wu, L.Z., Feng, J.C.: Energy absorption efficiency of carbon fiber reinforced polymer laminates under high velocity impact. Mater. Des. 50, 140-148 (2013)

43. Abaqus 2017 documentation. Dassault Systèmes. Provid Rhode Island, USA. 2017;

44. Frissane, H., Taddei, L., Lebaal, N., Roth, S.: SPH modeling of high velocity impact into ballistic gelatin. Development of an axis-symmetrical formulation. Mech. Adv. Mater. Struct. 3, 1-8 (2018)

45. Abdul Kalam, S., Vijaya Kumar, R., Ranga Janardhana, G.S.P.H.: High velocity impact analysis-influence of bird shape on rigid flat plate. Mater Today Proc. 4, 2564-2572 (2017)

46. Georgiadis, S., Gunnion, A.J., Thomson, R.S., Cartwright, B.K.: Bird-strike simulation for certification of the Boeing 787 composite moveable trailing edge. Compos. Struct. 86, 258-268 (2008)

47. Hashin, Z.: Failure criteria for unidirectional Fiber composites. J. Appl. Mech. 47, 329-334 (2015)

48. Liu, H., Liu, J., Kaboglu, C., Chai, H., Kong, X., Blackman, B.R.K., Kinloch, A.J., Dear, J.P. Experimental and Numerical Studies on the Behaviour of Polymer-Matrix Fibre-Reinforced Composites Subjected to Soft Impact Loading. Eng Failure Analysis. To be published

49. CYTEC. APC-2-PEEK Thermoplastic Polymer. 2012

50. Naderi, M., Khonsari, M.M.: Stochastic analysis of inter- and intra-laminar damage in notched PEEK laminates. Express Polym Lett. 7, 383-395 (2013)

51. Iannucci, L., Willows, M.L.: An energy based damage mechanics approach to modelling impact onto woven composite materials: part II. Experimental and numerical results. Compos Part A Appl Sci Manuf. 38, 540-554 (2007)

52. Kim, J.K., Sham, M.L.: Impact and delamination failure of woven-fabric composites. Compos. Sci. Technol. 60, 745-761 (2000)

53. Iannucci, L., Willows, M.L.: An energy based damage mechanics approach to modelling impact onto woven composite materials - part I : numerical models. Compos Part A Appl Sci Manuf. 37, 2041-2056 (2006)

54. Turon, A., Camanho, P.P., Costa, J., Renart, J.: Accurate simulation of delamination growth under mixedmode loading using cohesive elements: definition of interlaminar strengths and elastic stiffness. Compos. Struct. 92, 1857-1864 (2010)

Publisher's Note Springer Nature remains neutral with regard to jurisdictional claims in published maps and institutional affiliations. 